\title{
Investigation of geomechanical parameters of rock mass condition of Magnezitovaya mine**
}

\author{
Roman Krinitsyn ${ }^{1 *}$ and Sergey Sentyabov ${ }^{1}$ \\ ${ }^{1}$ Federal State Budgetary Institution of Science, Institute of Mining of the Ural Branch of Russian \\ Academy of Sciences, Ekaterinburg, Russia
}

\begin{abstract}
Mining is a sphere of human activity connected with extraction of minerals from Earth's interior in conditions of alternating change of the sizes of Earth accompanied by change of the stress-deformed state (SDS) of the rock mass, resulting in sudden destructions of rock structures and earthquakes, with considerable human victims.

The results of long-term geodeformation monitoring of natural stresses at Ural mines conducted by the Laboratory of geodynamics and mining pressure of the Ural Branch of Russian Academy of Sciences over the past 20 years have allowed us to offer new, more modern structure of the natural stress field with a reference to their changes in time. The Laboratory of geodynamics and mining pressure of the Institute of Geodynamics of the Ural Branch of Russian Academy of Sciences has created the geodeformation field test site at the Magnezitovaya mine [1] This field test site allows to quickly track the changes in the stress state by deformation methods and to react in time to the changes in the stress state of the rock mass. And by applying the measures to control the state of the rock mass, the company's personnel ensure the safety of room work at the deposit. This allows to minimize the occurrence of the rock pressure in static and dynamic forms, and thus to ensure the safety of people working in underground conditions. Keywords: deformation monitoring, rock mass control, stress-deformed state, flexible line method, slot unloading, stability of structural elements of development system.
\end{abstract}

\section{Introduction}

The Satka magnesite deposit is located in Satka District, Chelyabinsk Region, two kilometers north of the Satka railway station. The length of the deposit, which consists of seven sections (from the south-west to the north-east - Karginskiy, Severo-Karagayskiy,

\footnotetext{
${ }^{*}$ Corresponding authors: roman krinicyn@mail.ru

** The studies have been performed within the limits of the state order No. 075-00581-19-00 on the theme No. 0405-2019-0007
} 
Karagayskiy, Gologorskiy, Melnichno-Palenikhinskiy, Volchyegorskiy, Stepnoy), two of which (Volchyegorskiy and Stepnoy) are completely mined out, is about $10 \mathrm{~km}$ with the width of the ore-bearing streak of 500-700 m. Part of the magnesite deposits is located under the town of Satka and is mined by the Magnezitovaya mine (Fig. 1).

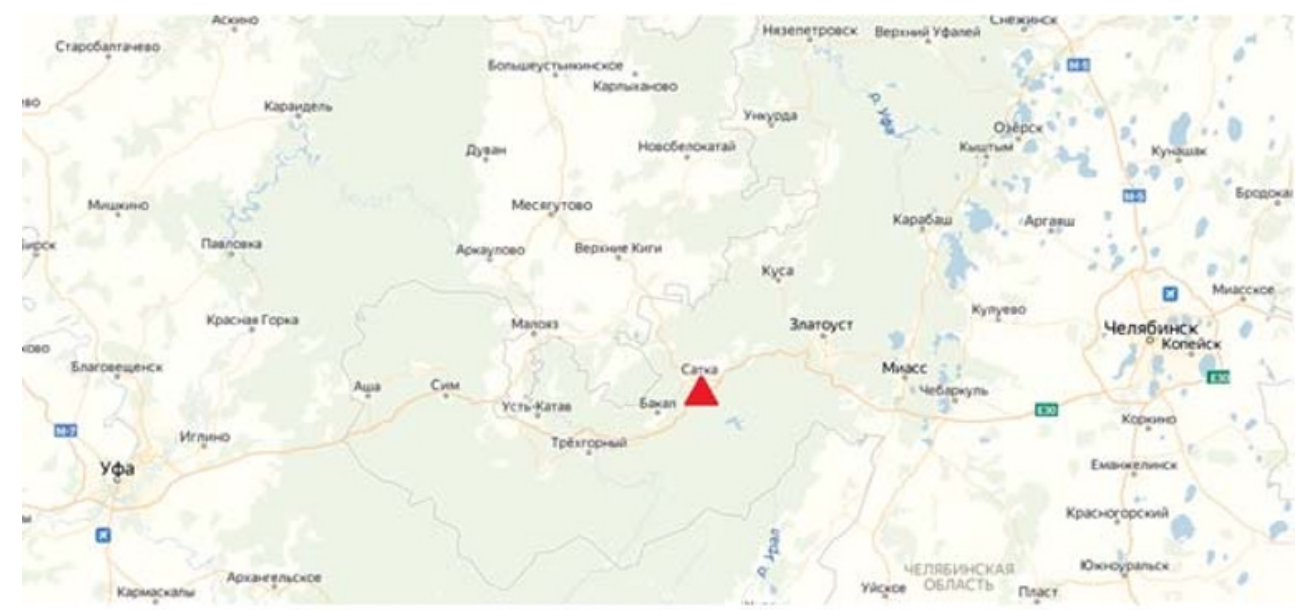

Fig. 1. Location of the Satka deposit

The Satka magnesite deposit (Southern Urals) is represented by a series of ore bodies of bedded and lenticular shape 1.3-3.6 km in length and 100-500 $\mathrm{m}$ in dip. The strike azimuth of ore bodies is $45-55^{\circ}$, the dip angles to South-East vary within the range of $10-85^{\circ}$, making an average of $30-45^{\circ}$. The normal thickness of ore bodies is in the range of $8-30$ m.

The dolomites (especially the layered ones) and the magnesites feature a system of sheet cracks with even, sometimes with slickenlines, surface. The crack system of North-East strike is oriented mainly according to the strike of the main folded structures. The introduction of dykes into the sedimentary strata took place in the weakened zones. The system of cracks of North-West strike cracks with steep dip to South-West strike (210$240^{\circ}$ ) was widely developed in the ore field. The veins of secondary dolomite, less often diabase dykes, are associated with this system [1, 2, 3, 4].

\section{Investigations of the geomechanical state of the rock mass}

Starting from 2019 the field mining will be carried out by the sublevel-chamber system with solid stowing. Taking into account the complexity of the rock mass, the encountered slickensides, tectonic disturbances and dykes and the level of natural stresses in the rock mass as well as the parameters of the mining system, the managers of the plant together with the staff of the Laboratory of geodynamics and rock pressure of the Institute of Mining of the Ural Branch of RAS have made a decision to create a geodeformation field test site whose task is to control the changes in the stress-deformed state of the rock mass.

The Laboratory of geodynamics and rock pressure of the Institute of Mining of the Ural Branch of Russian Academy of Sciences constantly studies the geomechanical state of the rock mass, which includes the study of physical and mechanical properties of ores and rocks of the deposit, the calculation of the changes in the stress-deformed state of the rock mass during the field mining. The Laboratory of geodynamics and rock pressure of the Institute of Mining of the Ural Branch of Russian Academy of Sciences has organized the geodeformation field test site to observe the changes in the stress state of the rock mass.

The field test site nowadays includes 5 different types of observation stations: 
- metering stations - deformation lines with length $\approx 50 \mathrm{~m}$ measured by the flexible thread method

- slot metering stations

- meter stations by photoelastic stress analysis

- automated rock pressure control station,

- automated seismometer control system Relos

Automated stations were designed and installed by the Institute of Mining of the Ural Branch of Russian Academy of Sciences together with the Research and Development Center Avtomatika, Krasnoyarsk.

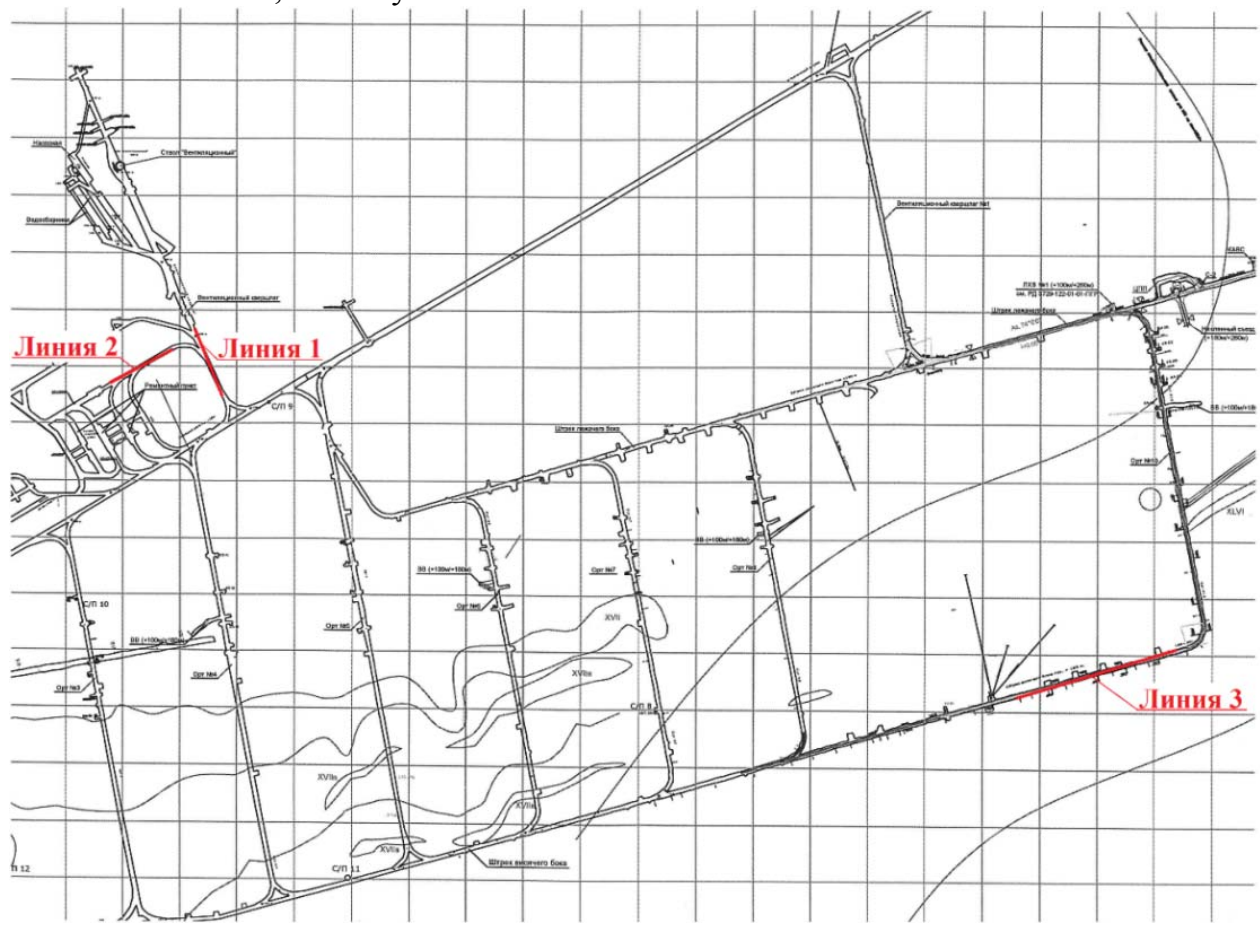

Fig. 2. Places of installation of deformation lines in the horizon $+180 \mathrm{~m}$

\section{Methods for measuring and calculating the pulsating component of tectonic stresses}

The study of the nature of variable stresses was as follows [6-10].

- A measurement base of $L_{0}$ long was selected, against which the change in the length of the reference line was estimated in subsequent measurements.

- At each measurement point for each direction of the reference lines the geological and tectonic structure of the sites was studied and the elastic parameters of the rock mass were estimated

$$
E_{\mathrm{M}}=0.9^{n} E_{0},
$$

where $E_{\mathrm{M}}, E_{0}$ are elastic moduli of the rock mass and sample, MPa; $n$ is the number of ranks of geoblocks based on reference lines.

- 3-4 cycles of observations per year are made at the geodynamic field test site by the method of distance between the reference points reduced to the horizon.

- The obtained changes in line length $\Delta L_{j}=\left(L_{j}-L_{0}\right)$ were used to determine the relative deformation of the rock mass $\varepsilon_{j}$. 
- According to the combination of measurements on three observation lines, the azimuths of which differ by more than $25-30^{\circ}$, the authors determined the changes in the magnitude of the horizontal stresses and azimuths of their action.

$$
\begin{gathered}
\operatorname{tg} 2 \alpha_{1-1}=\frac{\left(E_{I} \varepsilon_{I}-E_{I I} \varepsilon_{I I}\right) \sin ^{2} \alpha_{I-I I I}-\left(E_{I} \varepsilon_{I}-E_{I I} \varepsilon_{I I}-E_{I I I} \varepsilon_{I I I}\right) \sin ^{2} \alpha_{I-I I}}{\left(E_{I} \varepsilon_{I}-E_{I I I} \varepsilon_{I I I}\right) \sin 2 \alpha_{I-I I}-\left(E_{I} \varepsilon_{I}-E_{I I} \varepsilon_{I I}\right) \sin 2 \alpha_{I-I I}}, \\
\Delta \sigma_{1,2}=\frac{A(1+\mu) \pm\left(E_{I} \varepsilon_{I}-E_{I I} \varepsilon_{I I}\right)(1-\mu)}{B\left(1-\mu^{2}\right)},
\end{gathered}
$$

where $A=E_{I} \varepsilon_{I} \cos 2\left(\alpha_{I-I}+\alpha_{I-I I I}\right)-E_{I I I} \varepsilon_{I I I} \cos 2 \alpha_{I-I}$;

$B=\cos 2\left(\alpha_{I-I I}+\alpha_{I-I I I}\right)-\cos 2 \alpha_{I-I I}$;

$\alpha_{I-I I}+\alpha_{I-I I I}$ - angles measured counterclockwise from the first to the second and third reference lines, degrees;

$\alpha_{I-I}$ - action azimuth $\Delta \sigma_{1}$ measured from the direction $E_{\mathrm{I}} \varepsilon_{\mathrm{I}}$ clockwise, degrees;

$E_{I}, E_{I I}, E_{I I I}$ - moduli of deformation of the rock mass along the reference lines subject to the tectonics of the rock mass;

$\mu$ - Poisson's coefficient of the rock mass;

$\varepsilon_{I}, \varepsilon_{I I}, \varepsilon_{I I I}$ - relative deformation of the rock mass at the length of the reference lines.

- After statistical processing, the average values of $\Delta \sigma_{1}, \Delta \sigma_{2}$, and the azimuth of the maximum compressive stress $\alpha_{1}$ were obtained.

- For the whole period of observations, the mean azimuth of action $\Delta \sigma_{1}$ or $\Delta \sigma_{2}$, whichis taken to be the absciss $X$ axis, and $\Delta \sigma_{x}, \Delta \sigma_{y}, \Delta \sigma_{x y}$ were selected so that the mean values $\Delta \tau_{x y}$ were minimal.

Having performed the detailed study of the geological data of the deposit and the available mining and graphic documentation, the scientists of the Laboratory of geodynamics and rock pressure of the Institute of Mining of the Ural Branch of Russian Academy of Sciences have selected the locations of the observation stations, coordinating them with the technical management of the plant. The observation stations were installed and the measurements were taken 3-4 times per year. The analysis of the results of field studies has determined the occurrence of periodic changes in the SDS of the rock mass due to expansion and compression of the Earth's crust. Homogeneity and discrete structure of natural fields of the stress-deformed state of the rock mass determine the differential level of danger of its impact on the mining objects. Based on the results of the calculated stresses in the rock mass, the predicted stresses at the sites where the measuring stations were installed may reach the maximum values, which requires constant monitoring. Such studies on monitoring and predicting the condition of the objects were considered in the papers [11-18].

The data obtained at the Satka deposit are consistent with the results of stress-time measurements of variables in the rock mass, conducted by the Laboratory of geodynamics and rock pressure since 1998. But the difference in stress values is explained by the different moduli of the rocks and the concentration of stress in the peripheral parts of the permanent mine openings. 


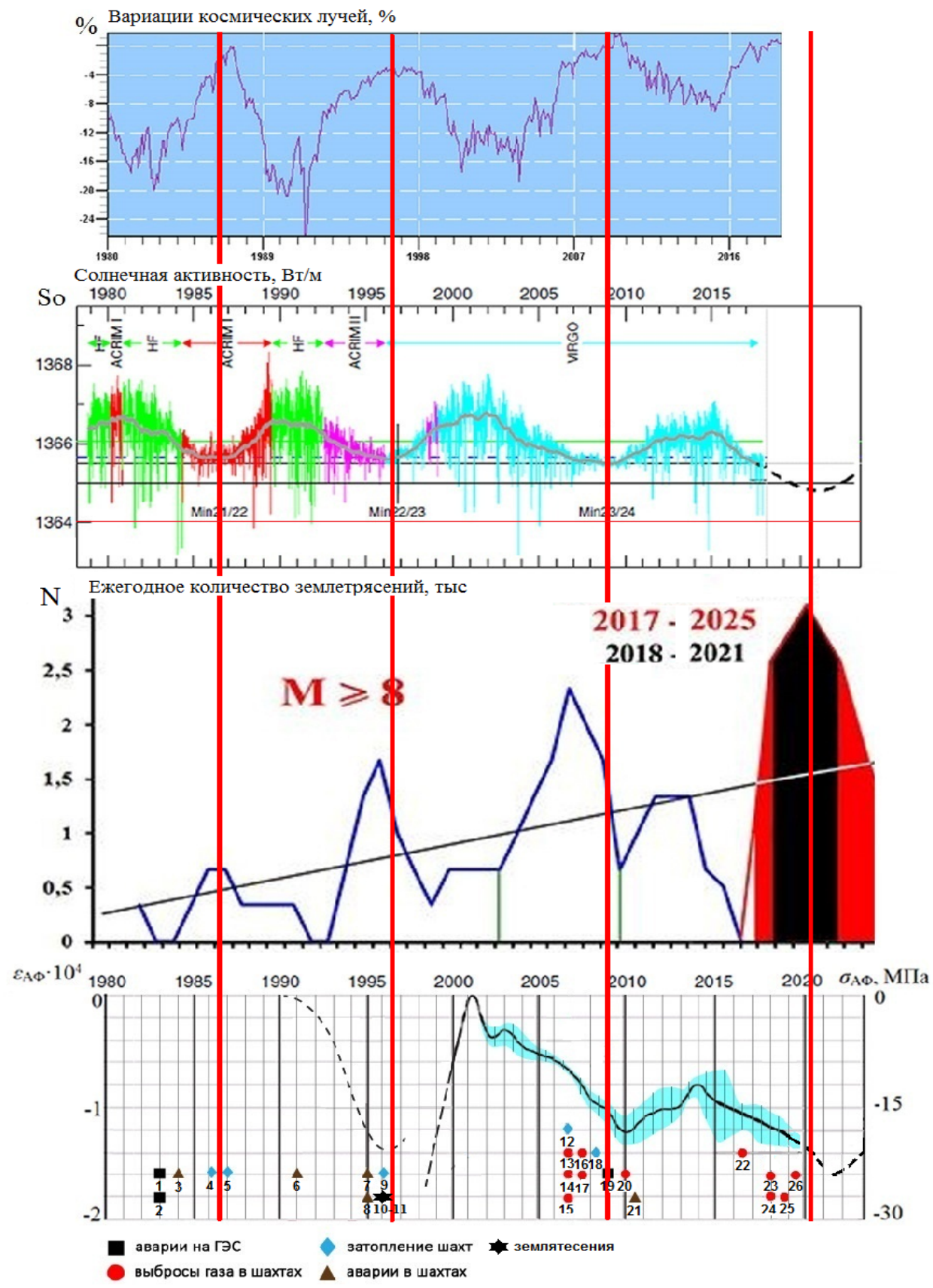

Fig. 3. The changes in the average values of the parameters of the stress-deformed state of the rock mass $\left(\left(\sigma_{\mathrm{A} \Phi}\right.\right.$ and $\left.\varepsilon_{\mathrm{A} \Phi}\right)$ in the Urals against the background of accidents at mines, the changes in the solar emissivity So, the intensity of cosmic radiation $\%$ and earthquakes $\mathrm{N}$.

The analysis of the performed studies has combined the results of long geodeformation monitoring of natural stresses at the mines of the Urals, being performed by the Laboratory of geodynamics and rock pressure of the Institute of Mining of the Ural Branch of RAS during the last 20 years and the measurements of stresses for 40 years in the basic mining 
regions of Russia and the world, which have suggested new, more current structure of the field of natural stresses with reference of their change to time.

\section{Conclusion}

To understand the processes occurring in the subsoil, it is necessary to constantly monitor the state of the rock mass and the stresses acting in it.

The geodeformation field test site equipped at the Magnezitovaya mine allows to monitor the rock mass condition during the stoped excavation. Sufficiently large volume of works is carried out by the experts of the Laboratory of geodynamics and rock pressure of the Institute of Mining of the Ural Branch of RAS at regular visits to the enterprise, supplementing the instrumental measurements with visual inspection of the rock mass. It allows to react in due time to changes of the stress state of the rock mass and to make changes and additions to the production technology if necessary.

The stress-deformed state of the solid rock mass is formed as a result of gravitational, tectonic and variable stresses. The gravitational component of stresses is found by calculation $(\gamma H)$, and the tectonic component can be measured only experimentally at the specific deposit, and it is within the limits of 0-40 MPa. And the variable component is fixed as a single one for the whole Earth's crust within 0-20 MPa, and its growth rate till 2022 is predicted to be 3-4 MPa per year. It is the variables "astrophysical" stresses that, when combined with gravitational and tectonic components of the rock mass, initiate technological disasters during the periods of extremes.

\section{References}

1. R. V. Krinitsyn, Mining Information Analytical Bulletin, 3-1, 105 (2020)

DOI: 10/25018/0236-1493-2020-31-0-105-115

2. R. Krinitsyn, A. Avdeev, S. Khudyakov, E3S Web of Conferences, p. 02017

3. E. V. Shevlyakov, I. S. Shelkoviy, Innovative geotechnologies at development of ore and non-metallic deposits p. 207 (Ekaterinburg, 2016) [in Russian]

$4 . \quad$ I. Yu. Rasskazov, G. A. Kursakin, M. I. Potapchuk, et al., Physical and Technical Problems of Mining, 5, 135 (2012)

5. A. V. Zubkov, Yu. G. Pheklistov, Ya. I. Lipin, S. V. Khudyakov, R. V. Krinitsyn, Mining Problems, 4(11), 41 (2016)

6. Yu. G. Pheklistov, A. V. Zubkov, R. V. Krinitsyn, Industrial safety, 12, 22 (2017)

7. Ya. I. Lipin, R. V. Krinitsyn, Modern Mechanics Problems, 33 (3), 410 (2018)

8. R. V. Krinitsyn, V. I. Polkhovskiy, S. V. Khudyakov, Mining Problems, 1(16), 22 (2018)

9. A. V. Zubkov, S. V. Sentyabov, K. V. Selin, Physical bases of rock destruction prediction: theses of reports of XI All-Russian school-seminar with international participation (Perm, 14 - 18 October 2019), Ed. by G. A. Sobolev, (Institute of Earth's Physics of RAS, Moscow), 24 - 25. (2019)

10. A. V. Zubkov, S. V. Sentyabov, Earth and Environmental Science: FarEastCon International Multidisciplinary Conference on Industrial Engineering and Modern Technologies, Vladivostok, Russky Island, 1-4 October 2019 459(3), 042082 (Far-East Federal University, Vladivostok, 2020).

11. CUI Xi-min, LI Chun-yi, YUAN De-bao et al. Journal of Hunan University of Science \& Technology (Natural Science Edition), 2, 1-4 (2009) 
12. JIANG Fu-Xing, YANG Shu-Hua, CHENG Yun-Hai et al. Chinese Journal of Geophysics, 5, 1511-1516 (2006)

13. Lan Tianwei, Zhang Hongwei, Han Jun et al. Journal of Mining \& Safety engineering, 29(6), 840-845 (2012)

14. Yu Lijiang, I. M. Batugina, A. S. Batugin, Science and Education: materials of the VI international research and practice conference, Munich, June $27^{\text {th }}-28^{\text {th }}$, 2014, 474-477 (Publishing office Vera VerlagWaldkraiburg-munich-Germany, 2014)

15. R. P. Shemetov, Mine Surveying and Mining, 1, 54 (2015)

16. K. V. Morozov, V. I. Ekgart, Mining Information and Analytical Bulletin, 7, 516 (2015)

17. S. A. Bornyakov, D. V. Salko, Physical and Technical Problems of Mining, 2, 172 (2016)

18. A. V. Leontiev, T. V. Lobanova, Interexpo Geo-Siberia, 4, 133 (2014) 